\title{
Apatía social y mal de amores: la relación emocional entre amor y migración en Paseador de perros (2008) de Sergio Galarza y Entre el cielo y el suelo (2008) de Lorenzo Helguero
}

Resumen: Partiendo de la alta carga de emocionalidad que se puede observar en los debates políticos actuales frente a la migración, el artículo presente analiza dos obras literarias -Paseador de perros (2008) de Sergio Galarza y Entre el cielo y el suelo (2008) de Lorenzo Helguero- en las que tanto los autores como los protagonistas migraron del Perú al Norte; esto corresponde a Europa, España y Madrid en Paseador de perros y a América del Norte, Estados Unidos y Washington en Entre el cielo y el suelo. Se tratará de responder a dos preguntas: ¿cómo, en ambas obras, el amor está vinculado a las respuestas emocionales provocadas por el contexto de migración?, y ¿en qué medida se distinguen las dinámicas emocionales presentadas en los dos textos? A partir del análisis de los aspectos emocionales que se basará en las reflexiones teóricas de Price (2015), Svašek (2010), Boccagni y Baldassar (2015) y Fredrickson (2001) se apreciarán tanto las semejanzas como los modos diferentes de los dos protagonistas de responder, a nivel emocional, a la situación migrante. Se mostrará cómo la literatura, gracias a su dimensión subjetiva, puede contribuir a relativizar e interrogar tales discursos emocionalizados.

Palabras clave: migración, América Latina, amor, emociones, literatura peruana

Varios gobiernos actuales del Norte aprovechan el tema de la migración desde el Sur Global para evocar respuestas emocionales, ante todo negativas, tales como el miedo o incluso el odio, por parte de sus posibles electores. Otros individuos receptores, en cambio, quizá desarrollen las mismas respuestas emocionales, pero no frente a los sujetos migrantes, sino con respecto a los mismos emisores de tales mensajes. De manera que la migración, entendida por Jochen Oltmer (cf. Oltmer 2016: 19) en un sentido amplio como formas de desplazamiento a largo plazo, se convierte en un tema de alta carga emocional para la

Hanna Nohe, Rheinische Friedrich-Wilhelms-Universität Bonn 
sociedad receptora, como señalan igualmente Paolo Boccagni y Loretta Baldassar (cf. Boccagni / Baldassar 2015: 74). Sin embargo, ¿cuáles son los procesos emocionales que experimentan los propios sujetos migrantes?

La literatura, en su cualidad de medio subjetivo, se presta de manera idónea para expresar y representar procesos emocionales y, por tanto, la experiencia emocional de la migración a los que no han migrado al igual que a los que comparten la experiencia y se ven reflejados en el relato. De este modo, puede servir de medio para crear empatía y así aumentar la comprensión de la sociedad receptora, así como para potenciar la auto-estima y el empoderamiento de los colectivos afectados. De hecho, motivada por diferentes razones, la migración implica varias consecuencias para los sujetos migrantes: se alteran los contactos sociales y sus costumbres culturales y los sujetos obtienen el estatus de extranjero. No obstante, las respuestas emocionales son múltiples. Según indican Boccagni y Baldassar, "hope and nostalgia, guilt and ambition, affection and disaffection" (Boccagni / Baldassar 2015: 73) son emociones típicas y dicotómicas de una vida migrante. En un panorama emocional tan dinámico no es de sorprender que el sentimiento del amor se vea afectado de igual manera.

Entre el cielo y el suelo (2008) de Lorenzo Helguero y Paseador de perros $(2009 \text { [2008] })^{1}$ de Sergio Galarza, dos novelas escritas por autores de origen peruano y relatadas por narradores autodiegéticos, en las que tanto el autor como el protagonista se han desplazado de Lima hacia el Norte, tematizan el desamor en el contexto del desplazamiento. Así, en Entre el cielo y el suelo el protagonista, Carlos, se desplaza a Estados Unidos, a Washington, en concreto, tras haber perdido su empleo como periodista para la columna "Sociales" en el periódico peruano El Comercio. La novela consta de cinco capítulos narrados por voces diferentes, siempre en primera persona, pero en géneros diferentes, como apunta también Fredrik Olsson (cf. Olsson 2013: 192): ${ }^{2}$ la del protagonista Carlos que aparece en un monólogo interior, dirigido a su ex-novia Clara, la de su mejor amigo Rodrigo que se expresa igualmente en un monólogo interior, su propia ex-novia en forma de un diario (los últimos dos desde Lima), su primo

1 El libro fue publicado por vez primera en 2008 en Lima, por la sede peruana de la editorial Alfaguara. Para el artículo presente se recurre, por razones de disponibilidad, a la segunda edición española, publicada en 2009 y reeditada en 2013 por Candaya en Barcelona.

2 Véanse igualmente los artículos que Fredrik Olsson y la propia autora contribuyeron al volumen ¿Un 'sueño europeo'?, editado por Verena Dolle (2020). Olsson analiza Entre el cielo y el suelo junto a otras obras de autores de origen latinoamericano, destacando al sujeto migrante como sujeto heterogéneo en el sentido de Antonio Cornejo Polar. La autora, por su parte, examina la situación subalterna y precaria de los sujetos migrantes en Entre el cielo y el suelo y El síndrome de Ulises (2005) de Santiago Gamboa. 
Foncho en Washington que se dirige directamente a Carlos que está a su lado, pero cuyas respuestas no aparecen sino de manera implícita, y la voz grabada del protagonista unos años antes. En Estados Unidos Carlos espera hallar trabajo más fácilmente (cf. CS: 11$){ }^{3}$ Su deseo es trabajar como redactor en revistas hispanas de Estados Unidos, como Washington Hispanic. En realidad, sin embargo, ninguno de los periódicos que contacta lo contrata. Por el contrario, trabaja como cajero en el supermercado Safeway, al menos durante los primeros meses tras su llegada, relatados por la novela. En Paseador de perros el protagonista, que se desplaza de Lima a España, específicamente a Madrid, tras empleos varios termina trabajando como paseador de perros. Este trabajo, coordinado por su jefe JFK, consiste en llevar a pasear a los animales de los suburbios de Madrid.

Ambos textos comparten, además de la migración de Lima hacia el hemisferio norte y la situación ilegal del protagonista (cf. CS: 12; PP: 61), la implicación de una historia de amor en el mismo proceso de migrar: en Entre el cielo y el suelo, la pareja del protagonista lo abandona después de que él haya partido hacia Washington con la idea de que ella lo seguiría; en Paseador de perros, ella lo deja después de haber migrado con él y haber pasado varios meses juntos en Madrid. En ambos casos, la relación se destroza, con la diferencia de que una pareja migró unida y la otra no.

En las siguientes páginas se tratará de responder a las preguntas de cómo, en ambas obras, la emoción del amor y, por tanto, la relación amorosa están vinculadas a las respuestas emocionales provocadas por el contexto de migración, $\mathrm{y}$ en qué medida las dinámicas emocionales presentadas en los dos textos se distinguen. Para ello, en primer lugar se discutirá la definición de emoción y se presentarán los procesos emocionales que caracterizan a la migración en general. A continuación, se analizará cómo dichos procesos emocionales se expresan en las dos obras literarias. Por último, se indagará el papel del amor y su vinculación a las demás emociones relacionadas con el desplazamiento. Mientras Cecilia Esparza en su artículo sobre "Peruanos en el mundo" destaca las semejanzas entre ambas novelas (Esparza 2008: 177), este artículo mostrará a partir del análisis de la articulación de las emociones en lo que se diferencian.

3 Para facilitar la lectura, a partir de aquí en adelante, las referencias a Entre el cielo y el suelo y a Paseador de perros se indicarán con las siglas CS y PP respectivamente, seguidas del número de página. 


\section{Definición de emoción}

En lo tocante a la definición de emoción, de manera general, Carolyn Price en su monografía titulada Emotion (2015) se refiere a las emociones con el término "emotional response" (Price 2015: 2), subrayando así ante todo los efectos físicos, visibles y perceptibles de una emoción. Como ejemplos de respuestas emocionales personales Price menciona, entre otros, la vergüenza, la ira, el miedo, la envidia, la indignación, el resentimiento, el dolor y el propio amor (cf. Price 2015: 6), emoción clave de las obras aquí presentadas en la que se centrará la segunda parte de este análisis. Price diferencia, además, la duración de la respuesta emocional de una persona; discierne, de modo simplificado, entre la reacción, el episodio y la actitud (cf. Price 2015: 2-6). Mientras que la primera dura pocos segundos, el episodio puede durar de unos minutos hasta varias semanas, y la última es "enduring emotional response" (Price 2015: 6), de modo que se convierte en el "significant theme in his life" (Price 2015: 6).

En esta línea se sitúa igualmente la definición de Maruška Svašek, quien en el artículo titulado "On the Move: Emotions and Human Mobility" e incluido en el volumen monográfico Emotions and Human Mobility (2010), editado por ella, examina los vínculos entre las emociones y el desplazamiento. Si bien Svašek emplea el término "proceso" en lugar del de "respuesta", esta hace igualmente hincapié en el aspecto físico de las emociones, pues describe los procesos emocionales como "discourses, practices and embodied experiences" (Svašek 2010: 869). Esta definición, por un lado, subraya el contexto cultural de cómo se expresan y perciben las emociones a nivel verbal y corporal; por otro, enfatiza la interacción con el mundo que nos circunda (cf. Svašek 2010: 868-869).

Ni Price, ni Svašek distinguen entre emociones positivas y negativas. Sin embargo, tal diferencia se mostrará reveladora para el análisis de ambas obras literarias, por lo cual se incluye la definición que Barbara L. Fredrickson emplea en su artículo "The Role of Positive Emotions in Positive Psychology" (2001). Como ejemplos de tales emociones Fredrickson aporta alegría, interés, contento y amor, mientras que la ansiedad, la tristeza, la rabia y la desesperación las evalúa como emociones negativas (cf. Fredrickson 2001: 218). La psicóloga las distingue ante todo con respecto al comportamiento que las emociones provocan en el sujeto que las experimenta. Así, las sensaciones positivas suelen incitar al individuo a entrar en relación con su alrededor y a participar en actividades colectivas (cf. Fredrickson 2001: 219). Como su artículo se centra en las emociones positivas, los efectos de las negativas permanecen implícitos: entrañarán comportamientos contrarios a las positivas, esto es, disminuirá la motivación del individuo para relacionarse con los sujetos que lo rodean, reduciendo así su actividad y 
aumentando la sensación de soledad. En el análisis literario esta distinción se mostrará particularmente indicadora con respecto a la relación entre el amor y los demás procesos emocionales vinculados a la migración.

En efecto, el desplazamiento provoca emociones particulares en el sujeto migrante, ante todo en lo que se refiere a los otros, como señalan Boccagni y Baldassar (cf. Boccagni / Baldassar 2015: 74). Estos otros equivalen a los sujetos que no se desplazan y que rodean a los que migran: corresponden tanto a las personas que forman parte de la sociedad de llegada como a las que han permanecido en el lugar de origen. Svašek señala que este entorno puede ser representado no solo por otros seres humanos, sino también por animales y objetos (cf. Svašek 2010: 868). Este aspecto resultará importante para el análisis de Paseador de perros.

En lo que a la sociedad de llegada se refiere, Boccagni y Baldassar subrayan que la política influye en las respuestas emocionales que los autóctonos experimentan frente a los migrantes (cf. Boccagni / Baldassar 2015: 74), lo cual influencia, a su vez, las emociones de los propios migrantes. Así, algunos políticos en sus discursos crean una imagen estereotipada del migrante que molesta la paz social, roba los empleos y pone en peligro el bienestar de la sociedad. Tales discursos generalizadores provocan emociones negativas como la xenofobia y el miedo frente a los migrantes (cf. Boccagni / Baldassar 2015: 74). Por consiguiente, los migrantes tienen la sensación de ser intrusos y se sienten indeseados. Por otro lado, con respecto a la familia y a las personas que han permanecido en el lugar de origen, los mismos sociólogos apuntan hacia los cambios producidos por los nuevos medios: "emotional lives are no longer conducted solely in proximity, but are increasingly performed, practiced and displayed in a variety of situated and simultaneous interactions, including across distance and space and over time" (Boccagni / Baldassar 2015: 74), lo que aparecerá en Entre el cielo y el suelo.

Sin embargo, lo que ni Svašek ni Boccagni y Baldassar mencionan, pero que aparece en ambas obras analizadas, es la interacción emocional del sujeto migrante frente a otros inmigrantes en la sociedad de acogida. Aquí influye, tal como en las emociones de los no-migrantes, el discurso político, aunque sea de manera implícita. En el análisis serán de interés sobre todo las emociones de los mismos sujetos migrantes, ya que estos son los narradores y protagonistas que expresan y presentan sus reacciones personales. Por tanto, en el siguiente apartado se examinarán las respuestas emocionales del sujeto migrante en Paseador de perros y Entre el cielo y el suelo respectivamente. 


\section{Respuestas emocionales del sujeto migrante en Paseador de perros y Entre el cielo y el suelo}

Tal como se presentó en el apartado anterior, la migración implica diferentes grupos sociales con los que el sujeto migrante se puede hallar confrontado a nivel emocional. En concreto, se puede tratar de la sociedad en la que se halla antes de partir, la sociedad de llegada, objetos no-humanos -animales inclusive-, otros migrantes y las personas que se han quedado en el país de origen. Todos estos grupos son tematizados en los textos.

Antes de entrar en detalles con respecto a los grupos sociales, constatemos que Paseador de perros menciona el modo de tratar emociones de manera general y explícita. Así, su jefe le aconseja al protagonista cómo gestionar sus emociones, según relata el narrador: “[Jota, el jefe] [m]e explicó un par de trucos para despejar la rabia y sobreponerme a los bajones de ánimo” (PP: 16). La rabia y los "bajones de ánimo" corresponden a procesos emocionales negativos según Fredrickson. Por tanto, el personaje del jefe implícitamente da a entender que tales emociones han de ser modificadas para obtener emociones positivas. Probablemente, esta actitud se vincula a su interés en fomentar una buena relación con los dueños (cf. PP: 43), ya que espera que las emociones positivas favorezcan su negocio (cf. PP: 43.).

\subsection{Emociones negativas antes de partir}

Contrariamente a lo que le sugiere su jefe, el narrador autodiegético de Paseador de perros se presenta a sí mismo como proclive a las emociones negativas: "Una de las cosas que más odio es que alguien me interrumpa para preguntar cómo me siento” (PP: 7). El odio, aunque en este caso no se trate de odio frente a personas, sino frente a comportamientos, ha de categorizarse como emoción negativa, pues conlleva un rechazo y, por tanto, implica la ausencia de actividad. En este ejemplo, el odio representa menos una respuesta emocional espontánea, sino más bien una actitud emocional en términos de Price, ya que se repite en situaciones semejantes. El narrador reincide en tal actitud emocional negativa, destacando a la vez su posición general frente a las emociones: “odio los sentimentalismos y me da la impresión de que Jota, el dueño del mundo, sufría de dicha enfermedad" (PP: 54). Aquí el protagonista no solo subraya su actitud de odio: su rechazo hacia lo que él denomina "sentimentalismos" indica que repudia mostrar sus emociones de manera general. Se trata pues de un aspecto caracterizador del protagonista migrante de Paseador de perros. Aunque 
no todas las emociones están vinculadas automáticamente al desplazamiento, tal como lo advierte Svašek (Svašek 2010: 867), esta característica influye en su relación con otros seres y confirma asî las observaciones de Fredrickson de que las emociones negativas reducen la motivación a relacionarse con otras personas, como se verá en adelante.

En lo que se refiere a las respuestas emocionales vinculadas a la migración, antes de partir, en la sociedad de origen ambos protagonistas experimentan, tal como señala igualmente Cecilia Esparza (cf. Esparza 2008: 177) cierta frustración: en Paseador de perros, el narrador llega a la conclusión de que "no valía la pena quedarse estacionado en una misma ciudad, y menos en Lima” (PP: 8). Aunque, correspondiendo al carácter apenas destacado del personaje, este no expresa su sensación emocional, los adjetivos “estacionado” y "misma” aluden a una ausencia de actividad y, por tanto, siguiendo las reflexiones de Fredrickson, implican sensaciones negativas. En Entre el cielo y el suelo el personaje Carlos experimenta un estancamiento comparable: "Yo estaba harto de escribir y tomar fotos para las páginas sociales de El Comercio [...]” (CS: 10). De nuevo, el adjetivo - "harto"- señala la impresión de monotonía, impresión que el narrador vincula a la situación económica del país: "era la caída de la bolsa, la crisis, la puta economía, el túnel en el que nunca se ve la luz” (CS: 11). Fredrik Olsson observa igualmente el "descontento generalizado [que el protagonista experimenta] de la situación social y económica” (Olsson 2013: 199) de Perú, su país de origen, "en el contexto de la crisis económica y el gobierno autoritario de Fujimori” (Olsson 2013: 198-199). De esa manera, en Entre el cielo y el suelo se indican claramente los factores externos que producen reacciones emocionales de frustración y, por consiguiente, la decisión de partir. En Paseador de perros las causas externas no pueden sino ser intuidas a base de la alusión ya citada: "y menos en Lima”. Ambos personajes parten, pues, debido a reacciones emocionales negativas frente a su país y a la ciudad de origen.

\subsection{Marginación emocional en la sociedad de llegada}

Ahora bien, tras el trayecto migratorio, en la sociedad de llegada la situación no es mucho mejor a nivel económico para los dos sujetos migrantes: para el protagonista de Entre el cielo y el suelo trabajar como cajero en un supermercado es el único modo para sobrevivir (cf. CS: 13); el de Galarza lo hará paseando perros (cf. PP: 7). Efectivamente, en Paseador de perros, la impresión de hallarse al margen de la sociedad crea nuevamente una sensación de frustración, comparable a la sentida con anterioridad a la migración. Esto se muestra en las siguientes palabras del narrador: "El placer del paseador de perros: husmear en 
pisos y casas extrañas [...]. Las ventajas: esos paseos impagables por el parque Retiro en una tarde fresca [...]. La realidad [...], eres el empleado de un perro" (PP: 51). La enumeración de los aspectos del trabajo comienza con lo positivo y se concluye con el estatus social de empleado: el hecho de servir a animales, relación que suele ser inversa, subraya la posición inferior de este sujeto migrante en la escala social (cf. PP: 12). A nivel emocional, el sustantivo "placer" alude a una respuesta positiva. En la última frase, en cambio, aunque no se explicite una emoción concreta, la ausencia de connotación positiva de "realidad" y la baja posición social mencionada apuntan hacia la desilusión.

La interacción con los miembros de la sociedad de llegada y las emociones que tal interacción desencadena están relacionadas con la situación socioeconómica, pero esta se representa de manera diferente en las dos novelas. En Entre el cielo y el suelo, verbigracia, Carlos se relaciona solo lo mínimo necesario con los estadounidenses como cajero. El paseador de perros igualmente entra en contacto con los autóctonos ante todo a través de su trabajo, pero de manera más intensa e íntima: "Pasear un perro o cuidar cualquier animal es como leer el diario de su familia” (PP: 43). Tanto entrando en sus casas como charlando con los dueños de los perros al llegar y al partir, trata con personas del país, a menudo de manera repetida, lo cual da lugar a interacciones y reacciones emocionales. Así, en una ocasión en la que el protagonista pasea por primera vez un perro de una nueva clienta y su jefe lo acompaña, el protagonista es confrontado con la xenofobia mencionada por Boccagni y Baldassar: "Entonces [la chica] empezó a quejarse de los inmigrantes, esa gente que no respeta nada. Jota me miró y le devolví una sonrisa. A los españoles viejos no les gusta que lleguen tantos extraños a su país. Dicen que atentan contra sus costumbres” (PP: 49). En este recuento el narrador no menciona, ni siquiera de manera alusiva, las emociones que experimenta él mismo al oír la actitud xenófoba de la dueña del perro. La reacción mímica que refleja - “una sonrisa”- en este caso expresa complicidad con su jefe e insinúa la sensación de impotencia frente a una situación de poder en la que el protagonista, en cuanto sujeto migrante, se siente jerárquicamente inferior. El resultado es una distancia emocional: en lugar de enojarse, el narrador explica la reacción emocional de la chica, que sirve para generalizar la caracterización de la sociedad de llegada, insinuada por el adjetivo “viejos”, que en este caso no se relaciona a la edad, sino a la situación residencial de los habitantes. No obstante, hablando de “españoles viejos”, el narrador crea una analogía con cristianos viejos en oposición a cristianos nuevos, categorías que se empleaban en la España de los Reyes Católicos. De esta manera, los españoles viejos se oponen a los nuevos, representados por los inmigrantes. La analogía alude a la nobleza que se les atribuía a los cristianos viejos y a un ambiente de sospecha y odio frente a los prójimos, ambiente que se asemeja a la xenofobia mencionada. 
La distancia emocional que el narrador prueba en esta cita corresponde al rechazo de emocionalidad, constatado anteriormente con respecto al protagonista.

En efecto, la indiferencia del paseador de perros se realza cuando el narrador describe su actitud general frente a los dueños de los perros:

Mi jefe me aconsejaba que mantuviera una buena relación con los dueños [...]. A mí me daba igual, trabajaba para comer y sabía que si me cruzaba con los dueños les caería en gracia por una extraña razón. Quizás interpretaban mi silencio como sumisión. Nunca les llevaba la contraria porque el cansancio me derrotaba frente a las instrucciones que me repetían una y otra vez [...]. (PP: 43)

El comentario "me daba igual" reitera la supresión de emociones del protagonista, que el narrador explica a través de su actitud pragmática a la hora de trabajar. Considera su relación como parte del trabajo que lleva a cabo únicamente por necesidad económica, pues “trabajaba para comer”. Sin embargo, una razón ulterior que está vinculada a su situación migrante justifica su impasibilidad: está cansado por causa de los horarios impuestos por uno de los trabajos que logró obtener a pesar de su situación de migrante ilegal. Este cansancio le impide una interacción emocional con los autóctonos. Por ende, según lo presenta el narrador, la supresión de emociones es debida a la precaria situación socioeconómica del migrante.

En cambio, frente a los animales, que forman igualmente parte del mundo circundante, según lo define Svašek, las reacciones del paseador de perros son más afectivas. Él mismo lo confirma de manera explícita: “Amo a los perros, recojo su mierda y la de sus dueños cuando me cuentan sus problemas; controlo mis ganas de matar al idiota que se atreve a llamarme la atención cuando el perro caga enfrente de su portal" (PP: 28). El verbo "amo" nombra expresamente una emoción positiva y se opone a las negativas expuestas anteriormente. ${ }^{4}$ Esta oposición entre la sensación positiva frente a los perros y la negativa respecto a las personas se refuerza por la expresión "mis ganas de matar al idiota”, pues indica una respuesta emocional negativa, de manera que el protagonista parece más cariñoso con los animales que con los humanos. Sin embargo, como esta reacción es causada por razones profesionales, resulta difícil averiguar si su emoción antecede a su comportamiento o si, al contrario, el comportamiento evoca la respuesta emocional, por lo cual la emoción sería nuevamente el resultado de una actitud pragmática.

4 Aunque desde un punto de vista léxico aquí se trata del amor, que constituye el enfoque del próximo apartado del artículo, en el ejemplo presente el amor ha de ser entendido como una actitud emocional que se distingue del amor por una persona tal como será analizado en adelante. 
Efectivamente, otro ejemplo de la amabilidad que el protagonista expone frente a los animales sugiere que la demostración de emociones positivas frente a las mascotas es inducida por razones pragmáticas. Aparte de los perros, el protagonista cuida a un mapache llamado Odo, nombre que hace pensar en odio y crea así un juego de palabras con una emoción. En lugar de pasearlo, la tarea consiste en limpiar su jaula. El protagonista se comporta de la siguiente manera: "hablo con cariño a Odo y barro su mierda, rogando que no me muerda” (PP: 22). Los ruegos del personaje implican una sensación de miedo, de manera que quizá sea esta última emoción la que provoque la actitud cariñosa, con el fin de evitar una emoción negativa por parte del animal, ya que esta podría resultarle peligrosa al paseador de perros.

No obstante, la reacción emocional del miedo se va acumulando, a lo largo de las tardes (cf. PP: 22) en las que se encuentra con Odo, a tal punto que se convierte en episodio, aplicando los términos de Price: "Después de un mes limpiando la jaula de Odo, estaba al borde de un colapso nervioso. Temía y temo por mi vida cada tarde en Pozuelo cuando Odo muestra esos dientes que pueden atravesarme la mano como a un crucificado" (PP: 52). Debido a la repetición de la reacción emocional, esta se convierte en una sensación que perdura y conlleva consecuencias ulteriores tal como un "colapso nervioso" inminente. De nuevo, esta sensación no está vinculada sino de manera indirecta a la situación migrante del protagonista: habiendo inmigrado, ha de aceptar el trabajo que se le ofrezca y, consecuentemente, se encuentra en una situación un tanto agobiante.

\subsection{Distanciamiento de otros migrantes por razones emocionales}

Mientras que los residentes autóctonos y los animales aparecen ante todo en $E l$ paseador de perros, la presencia de y la emoción frente a otros inmigrantes se halla en ambas novelas, como indica igualmente Esparza (Esparza 2008: 177), especialmente en la figura de los compañeros de trabajo. En El paseador de perros, por ejemplo, como explica el narrador: "los paseadores de perros pertenecemos a un gremio minúsculo de inmigrantes. Un mexicano ilegal, una pareja de lesbianas venezolanas, una argentina de la pampa, mis compañeros y yo somos sus integrantes” (PP: 61). Los inmigrantes mencionados por una parte comparten el hecho de provenir de América Latina: México, Venezuela, Argentina y Perú. Por otra, los enumerados son, de un modo u otro, socialmente marginados, ya sea por la ilegalidad, la orientación sexual o el origen rural. Esta marginación que permanece implícita en el pasaje citado se vuelve una crítica más 
explícita en la página siguiente, cuando el protagonista describe su relación con dichos compañeros:

Perros y papeles de trabajo. ¿De qué más se puede hablar con una banda de inmigrantes que pasea perros y nunca ha escuchado a Baxter Dury, que no ha entrado al Garaje Sónico, que no ha pisado Malasaña? Todos viven atados a la nostalgia extrañando a sus familias y su comida. Yo no extraño ninguna de las dos, porque en vez de irme de Lima me largué y largarse es algo tan definitivo como la muerte. (PP: 62)

Con "banda de inmigrantes" el narrador expresa su desprecio y se distancia de sus colegas migrantes, aunque en rigor él mismo forma parte de ellos. Como lo expresa Athena Alchazidu, el protagonista "no se siente identificado [...] con la comunidad de los latinos” (Alchazidu 2014: 13). A través de la pregunta retórica en la que el paseador nombra sus intereses personales se presenta como migrante diferente. De hecho, describe una reacción emocional que Boccagni y Baldassar mencionaron como ejemplo típico de los migrantes: la nostalgia vinculada a la familia y a las costumbres del lugar de origen. No obstante, el narrador subraya su distinción afirmando que no experimenta ninguna de estas reacciones emocionales. De este modo, por un lado, se comprueba, una vez más, su distancia emocional; por otro, el narrador aparece como no vinculado a la patria y, por tanto, como migrante excepcional.

En Entre el cielo y el suelo el narrador autodiegético expresa una distancia semejante hacia sus compañeros de trabajo, igualmente por razones emocionales, pero esta vez de manera inversa: “A mis amigos salvatrucos [sic] del Safeway no [...] les he dicho nada [de mi mal de amores]. [...] [P]ensarían que soy un huevón. Con ellos voy a veces a jugar fulbito [...]” (CS: 16). Mientras que el protagonista de Paseador de perros se siente distante porque no comparte las emociones de sus colegas, Carlos en Entre el cielo y el suelo teme que ellos no comprendan el ímpetu con el que sus propias emociones inciden en su estado de ánimo. Ahora bien, en Paseador de perros las emociones no compartidas se refieren a la migración; en Entre el cielo y el suelo, por el contrario, Carlos no se siente comprendido frente a las emociones causadas por el desamor, tema que se retomará en el apartado 4.

Aun así, ambos protagonistas comparten la sensación de no ser comprendidos a nivel intelectual por sus compañeros inmigrantes. El personaje Carlos lo expresa del modo siguiente: "Lo jodido es no tener nadie con quién conversar sobre lo que leo [...]. [L]os salvadoreños de lo único que hablan todo el día es de fútbol y de comida centroamericana” (CS: 26). El narrador se siente incomprendido con respecto a sus intereses intelectuales, $\mathrm{y}$, en especial, con respecto a la lectura. Ante todo el último capítulo de Entre el cielo y el suelo, donde el protagonista graba su voz unos años antes en Lima, destaca su interés casi existencial 
por el cine y la literatura. Esto se muestra en particular en la convicción de que, en correspondencia con Rayuela de Cortázar, existe su propia "Maga” que él espera encontrar (cf. CS: 117-141). El paseador de perros, en cambio, hace hincapié en la música, pero es igualmente el gusto por el arte que lo distancia de sus compañeros migrantes. Ambos protagonistas experimentan una emoción de nostalgia menos fuerte frente a la comida del país de origen que sus compañeros de trabajo. En los ejemplos citados, los narradores expresan, además, ciertos prejuicios clasistas, según los que los migrantes “típicos” aparecen como desinteresados por la cultura, ya sea literatura, cine o música. Los protagonistas se representan, así, como anti-migrantes, pues no experimentan las emociones y los intereses que caracterizan a los migrantes marcados como típicos. ${ }^{5} \mathrm{El}$ aspecto de las emociones frente a la familia y a las personas que han permanecido en el lugar de origen será el tema del próximo párrafo.

\subsection{Abandono emocional de o por las personas cercanas en el país de origen}

El narrador de Paseador de perros no hace referencia a su familia sino recordando su actitud antes de partir. Así, el protagonista trata de convencer a su novia, Laura Song, a migrar con él, con el argumento de que el contacto con la familia permanece a pesar de la distancia: "Le dije [a Laura] que siempre tendría a su familia como un mapa de afectos que podría visitar cuando quisiera, y me creyó” (PP: 8). La expresión “mapa de afectos” designa expresamente a la familia como lugar de emociones positivas vinculadas al origen al que siempre se podrá recurrir. En cambio, “me creyó”, insinúa que esta posibilidad no corresponde a la realidad. Efectivamente, el protagonista afirma no extrañar a su familia, ya que "se largó", lo cual implica que tampoco mantiene el contacto, tal como se lo propuso a su pareja. De modo que, como se ha señalado en el apartado anterior, el paseador de perros parece no experimentar las emociones de nostalgia que describen Boccagni y Baldassar. El narrador explica la ausencia de este proceso emocional de la manera siguiente: "Nunca me han preocupado las cenas familiares ni los innumerables compromisos que acarrea participar de una familia [...]” (PP: 15). Describe un desinterés

5 Esta excepcionalidad de los protagonistas a nivel intelectual se opone, sin embargo, a su situación socioeconómica marginada, en la que se representan como corresponder perfectamente a la imagen estereotípica del migrante del Sur en el Norte Global. Véase mi contribución ya mencionada sobre la dimensión precaria de los sujetos migrantes (Nohe 2020). 
social que podría hacer referencia a emociones negativas. ${ }^{6}$ De esta manera, la apatía social se confirma como rasgo caracterizador del personaje. Esta característica incide en el hecho de que sus respuestas emocionales se distingan de las de otros sujetos migrantes, tal como se mostró en el apartado anterior.

En Entre el cielo y el suelo se hace una referencia implícita al contacto que el protagonista mantiene con su familia. Su primo Foncho, que se encuentra igualmente en Washington, alude al hecho de que Carlos le comentó a su madre haber encontrado trabajo como redactor, mientras que en realidad continúa trabajando en el supermercado a causa de no haber sido contratado por ninguna revista (cf. CS: 116). ${ }^{7}$ Dicha comunicación con la madre tiene que haber tenido lugar con uno de los nuevos medios que permiten una interacción simultánea que atraviesa espacios, tal como se indicó, según Boccagni y Baldassar, en la parte teórica. Una consecuencia que la comunicación por los nuevos medios implica para el sujeto migrante es que las personas cercanas que se quedaron en el país de origen solicitan novedades inmediatas a continuación. Esto puede causar una presión mental para el migrante, ante todo, cuando las noticias no son las deseadas, como es el caso del protagonista de Entre el cielo y el suelo. Así, para satisfacer la curiosidad y calmar las preocupaciones de su madre, Carlos le mintió. Aunque, tal como se ha mencionado en la nota, las respuestas emocionales de Carlos en ese capítulo quedan implícitas, su comportamiento frente a su madre presupone tanto empatía, pues la quiere calmar, como un sentido de culpa y vergüenza, ya que no osa invitarla a Washington: teme el momento en que su madre descubra su verdadera situación: no solo que sigue trabajando en la caja del supermercado, sino también que ha engordado unos diez kilos (cf. CS: 11).

No obstante, la atención de Carlos se centra en su ex-pareja Clara, que ha permanecido en Lima a pesar de haber prometido seguirle. Por lo tanto, Carlos experimenta una sensación de decepción y confusión: “dime por qué nunca viniste. Dime qué mierda estoy haciendo solo en Washington, Clara. Si ya lo teníamos todo decidido. [...] Yo me iría primero, y de ahí, cuando ya estuviera instalado, tú [...] vendrías conmigo, Clara [...]" (CS: 11). La pregunta y la palabrota implican una desilusión por parte del sujeto migrante. En este caso no

6 El rechazo de contactos aparece igualmente en la siguiente constatación: "Nunca me he preocupado de cultivar un mejor amigo" (PP: 15).

7 Como se trata del capítulo en el que tan solo aparece la voz del primo del protagonista, aunque sea en un diálogo con Carlos, las palabras y las sensaciones de Carlos quedan implícitas: "Mándale el pasaje a mi tía y que venga a visitarte, eso te haría bien. [...] Ojalá que pueda venir, eso te haría bien, de hecho. ¿Qué? ¿Y para qué le dijiste que ya te habían dado el trabajo de redactor?" (CS: 115-116). 
es el sujeto migrante que ha abandonado a la persona que se quedó atrás, sino al contrario: el migrante ha sido abandonado por su pareja. De esta manera se explica la frase paradójica: "Regresa, Clara, regresa [...] (aunque en términos mapamundi o almanaque mundial yo fui el que me fui)" (CS: 28). Carlos no echa de menos a Clara en el lugar de origen, sino en el de llegada: "Deberías haber venido, qué diferente sería todo" (CS: 26). Esta sensación de la nostalgia está vinculada a la del amor, una emoción que en ambas novelas acompaña el proceso de aclimatación en la nueva ciudad de residencia. Por lo tanto, en el apartado próximo se examinará el papel que dicha emoción juega con respecto a las demás reacciones relacionadas con el desplazamiento.

\subsection{El amor vinculado a las demás emociones relacionadas con el desplazamiento}

Tal como se expuso en el apartado teórico, el amor representa una sensación positiva, en términos de Fredrickson. De tal modo, en un principio el amor como emoción debería desencadenar una mayor interacción e implicación social por parte del sujeto que ama. ${ }^{8}$ En las obras analizadas, por el contrario, no se observa tal aumento de actividad, ya que más que amor, lo que exponen es el desarrollo del desamor.

En los apartados anteriores se ha insinuado que en ambas obras la emoción del amor y la relación con la pareja influye, de manera esencial, en las demás sensaciones vinculadas al desplazamiento. En Entre el cielo y el suelo, el sujeto migrante sigue enamorado tras desplazarse: "ni siquiera me diste una explicación, por qué carajo me dejaste, Clara. Si todo iba tan bien; al menos entre nosotros [...]" (CS: 10). Para el protagonista, antes de partir, el amor como emoción positiva representa un contrapeso a la sensación de frustración social, destacada en el apartado 2.1. Después del desplazamiento, Carlos sigue sintiendo amor por su ex-pareja, aunque ella haya cortado los lazos: "Después de tantos meses sigo enamorado de ti [...]” (CS: 16). No obstante, el hecho de que dicha emoción positiva no sea respondida crea sensaciones negativas: "Estoy con la tristeza a cuestas, Clara, quisiera por lo menos tener el consuelo del sueño [...]” (CS: 37). La tristeza, en cuanto emoción negativa causada por el

8 El hecho de que el amor sea una emoción positiva no impide que el estar enamorado pueda también llevar al aislamiento, ya que si los integrantes de la pareja son ambos migrantes, estos pueden crear un microcosmos familiar, en el que no precisan de ningún tipo de interacción con la sociedad. 
amor interrumpido, conlleva reacciones físicas como la imposibilidad de dormir. Además, induce una actitud flemática respecto a las personas que circundan al sujeto desamado, como se mostró en el apartado anterior. De esta manera se confirma la inactividad causada por emociones negativas, según Fredrickson, provocada por una emoción positiva no respondida. Olsson interpreta la añoranza por el amor perdido como nostalgia de tiempos mejores del país de origen del protagonista (cf. Olsson 2013: 204), interpretación que confirma la conexión entre las emociones vinculadas al amor y las relacionadas con la migración.

Mientras que en Entre el cielo y el suelo las sensaciones negativas son causadas por la emoción del amor que ya no es respondido por el sujeto amado y que el protagonista sigue experimentando a pesar de la interrupción de las relaciones, en Paseador de perros las sensaciones positivas, y por tanto también el amor, parecen disminuir a partir del primer día de noviazgo: "Confieso que el día en que nuestra relación empezó fue el más feliz que he tenido hasta ahora, sobre todo con la escasez de alegrías que atravieso" (PP: 8). El hecho de que el narrador recuerde el comienzo del idilio señala que el protagonista es capaz de experimentar emociones positivas, causadas por una relación social. Su rechazo de emociones, ante todo positivas, y el de lazos familiares o amistosos como actitud general podría ser causado, por tanto, por la frustración social que el personaje ha padecido tras la migración. En efecto, aunque la diminución de felicidad a partir del primer día de las relaciones podría implicar la ausencia de una emoción real de amor, parece ser, precisamente, la difícil situación económica por la inmigración que provoca emociones negativas, las cuales, a su vez, perjudican el amor:

\footnotetext{
Los actos reflejos se transformaron en obligaciones y la desobediencia cundió. No podía más con la rabia, no entendía por qué tanta precariedad, no sabía qué sería de nosotros el día que el dinero ya no alcanzara. Esto ponía en duda mi capacidad para vaciar la amargura que sentía por haberme equivocado al marcharnos de Lima, donde nos protegíamos de los problemas abrazándonos bajo la frazada de la seguridad que da el estar en casa. [...] No entendía cómo podía arrepentirme de haber dejado Lima. (PP: 20)
}

La precariedad produce rabia; el hecho de haberse equivocado frente a las posibilidades en el nuevo país, amargura. Estas emociones negativas causadas por la situación vivida tras la migración provocan reacciones emocionales y comportamientos que deterioran la relación de la pareja. De hecho, con "actos reflejos” el narrador se refiere a las reacciones emocionales y corpóreas frente a su novia, tal como el abrazarla. El episodio emocional de rabia le impide sentir el impulso espontáneo a tales reacciones, de modo que las percibe como obligaciones. Como él mismo observa, a pesar de que la precariedad económica sea la misma en ambos lugares, la sensación de incertidumbre social y cultural aumenta las emociones negativas. 
En consecuencia, la separación de la novia va a la par con el desarrollo de la vida en el nuevo lugar:

La ruptura con Laura Song sucedió al comienzo de esta primavera, cuando vivir en La Latina ya no me llamaba la atención, pues me parecía un barrio para gente adulta contemporánea, esa edad que se corresponde con un periodo de capitulaciones, sobre todo la aceptación de que las sorpresas desaparecen para ceder su lugar a la planificación. (PP: 9)

La ruptura parece resultar de un estancamiento de reacciones emocionales con respecto a la nueva zona. Aparte de la precariedad económica influye igualmente el grado de novedad del lugar de residencia. Mientras que al principio el barrio en el que el protagonista vivía le causaba reacciones emocionales positivas fuertes, estas van disminuyendo con la costumbre. La planificación que el personaje asocia a la edad adulta podría reflejar su sensación de normalidad tras haber migrado, lo que implica menos sorpresas y, por tanto, menos reacciones emocionales de euforia.

En tal situación confusa a nivel emocional, la soledad obtiene un efecto equilibrador para el protagonista de Paseador de perros, que contrasta con la observación de Esparza, quien interpreta la soledad del paseador de perros como patética (cf. Esparza 2008: 178), pero coincide con Zovko que constata que el protagonista percibe la soledad como único atractivo de su trabajo (cf. Zovko 2017: 61). Así, la soledad ayuda al protagonista a reflexionar sobre y controlar sus reacciones emocionales: "Los paseos me servían para despejarme, para controlar el cataclismo pues Laura Song y yo empezábamos a discrepar [...]” (PP: 19). De este modo, la soledad en Paseador de perros resulta ser una sensación positiva.

En Entre el cielo y el suelo, por el contrario, el protagonista percibe la soledad como sensación negativa, ya que en su caso la soledad no es una emoción momentánea, sino un episodio que perdura y que conlleva comportamientos inusuales, como explica él mismo: "Estoy solo, Clara. Y a veces la soledad lleva a hacer cosas que normalmente no harías. No es que me piense matar ni nada de eso, no soy tan dramático. Pero tampoco es que me interese mucho vivir [...]. Hace unos meses fui a misa [...]” (CS: 17). Para este personaje, la soledad debido al abandono por la novia produce una apatía vital que le dificulta participar en la vida social que lo circunda, tal como se ha destacado anteriormente. Mientras que el paseador de perros, de carácter apático, aprecia la soledad como emoción positiva, el protagonista enamorado la experimenta como negativa, ya que realza su mal de amores. 


\section{Conclusiones}

Al comienzo de este artículo se presentaron las preguntas de cómo los protagonistas de las dos obras analizadas, Entre el cielo y el suelo (2008) de Lorenzo Helguero y Paseador de perros (2009 [2008]) de Sergio Galarza, reaccionan a nivel emocional frente a las situaciones provocadas por la migración y cómo el desarrollo del amor se relaciona con tales emociones. En ambos casos, el desamor está vinculado de manera intrínseca con la migración y las emociones que esta desencadena, aunque se desarrolle de modos diferentes. En Entre el cielo y el suelo el protagonista continúa enamorado y sufre del hecho de que su pareja lo haya dejado, no migrando con él. En Paseador de perros, en cambio, la ruptura de la relación tiene lugar después del desplazamiento, debido, ante todo, a la precaria situación económica y social. En ambas narraciones el desplazamiento juega, pues, un papel esencial con respecto a la separación de la pareja.

El enfoque en las emociones ha permitido, además, esclarecer una diferencia fundamental entre los dos relatos. Los protagonistas y narradores autodiegéticos se distinguen precisamente por sus actitudes frente a las reacciones emocionales. Carlos en Entre el cielo y el suelo se presenta como un personaje emocional y sentimental, que se dedica completamente al amor sentido frente a su ex-novia que idealiza aun antes de conocerla como personaje literario de la Maga. Su situación como inmigrante está empañada por su mal de amores. Las emociones negativas que se desencadenan de tal situación le impiden entrar plenamente en contacto y superar su dolor a través de interacciones con la sociedad de llegada, ya sea esta representada por los estadounidenses autóctonos o por los demás inmigrantes, pues todas sus reacciones emocionales se centran en el desamor. El protagonista de Paseador de perros, por el contrario, se presenta como poco proclive a las respuestas emocionales en general. Mientras que la apatía de Carlos resulta ser un efecto del desamor, el paseador de perros se auto-representa por su indiferencia como rasgo personal. No obstante, el hecho de que mencione la felicidad insinúa que su actitud emocional negativa probablemente ha sido causada por la decepción respecto a su situación económica y social en la sociedad de llegada tras la migración. Aun así, presenta reacciones positivas, si bien estas aparecen ante todo en la interacción con animales en lugar de con personas.

No obstante, ambos personajes coinciden en la sensación de distinguirse de los demás migrantes. A parte de la no-comprensión del mal de amores, tanto Carlos como el paseador de perros se sienten incomprendidos en sus intereses intelectuales, ya sean estos musicales -en el caso del paseador- o literarios -en el caso de Carlos-. De hecho, es preciso subrayar que las reacciones emocionales de los dos sujetos migrantes que el lector percibe dependen de manera esencial 
del narrador autodiegético. Este selecciona las emociones que relata y por tanto elige igualmente la impresión que el receptor recibe del sujeto migrante a lo largo de la lectura. Aun así, se puede constatar que la situación socioeconómica que el sujeto migrante experimenta, debido igualmente a su estatus político de inmigrante indocumentado, influye no solo en su estilo de vida, sino también en sus reacciones emocionales. Tal introspección en los procesos emocionales de sujetos migrantes es posible a través de la perspectiva subjetiva que es inherente a la literatura y provoca la empatía por parte del lector. De este modo, aun sin mencionarlo de manera explícita, la perspectiva interna de los sujetos migrantes relativiza y por tanto interroga los discursos políticos simplistas actuales de ciertos líderes políticos populistas tanto en América del Norte como en Europa que generalizan al migrante como un peligro, provocando miedo y creando así un enemigo retórico del que prometen proteger a sus posibles electores.

\section{Bibliografía}

Alchazidu, Athena (2014): "La (ansiosa) vida en el paraíso: la migración en la sociedad contemporánea y su reflejo en la novela Paseador de perros de Sergio Galarza”. En: Ulašin, Bohdan (ed.): Quo vadis, Romanística? Bratislava: Universidad Comenius de Bratislava, pp. 9-17.

Boccagni, Paolo / Baldassar, Loretta (2015): “Emotions on the Move: Mapping the Emergent Field of Emotion and Migration". En: Emotion, Space and Society 16, pp. 73-80.

Esparza, Cecilia (2008): "Peruanos en el mundo. Narrativas sobre migración internacional en la literatura reciente”. En: Inti: Revista de literatura hispánica 67.1, pp. 173-184.

Fredrickson, Barbara L. (2001): "The Role of Positive Emotions in Positive Psychology. The Broaden-and-Build Theory of Positive Emotions". En: American Psychologist 56.3, pp. 218-226.

Galarza, Sergio (2009) [2008]: Paseador de perros. Barcelona: Candaya. Helguero, Lorenzo (2008): Entre el cielo y el suelo. Lima: Alfaguara.

Nohe, Hanna (2020): "Sueño y realidad en El síndrome de Ulises (2005) y Entre el cielo y el suelo (2008): la dimensión precaria de los sujetos migrantes de Santiago Gamboa y Lorenzo Helguero”. En: Dolle, Verena (ed.): ¿Un ‘sueño europeo’? Europa como destino anhelado de migración en la creación cultural latinoamericana (2001-2015). Madrid / Frankfurt a. M.: Iberoamericana / Vervuert, pp. 183-198.

Olsson, Fredrik (2013): "La constitución del sujeto migrante en Entre el cielo y el suelo, de Lorenzo Helguero”. En: Giuliani, Luigi / Trapassi, Leonarda / Martos, Javier (eds.): Far Away Is Here. Lejos es aquí. Writing and Migrations. Berlin: Frank \& Timme, pp. 191-209.

Olsson, Fredrik (2020): “Más allá del 'sueño americano': avances teóricos sobre el mito de la tierra prometida a partir de Entre el cielo y el suelo (2008) y Hot sur (2012)”. En: Dolle, Verena (ed.): ¿Un 'sueño europeo'? Europa como destino anhelado de migración en la creación cultural latinoamericana (2001-2015). Madrid / Frankfurt a. M.: Iberoamericana / Vervuert, pp. 141-160. 
Oltmer, Jochen (2016): Globale Migration. Geschichte und Gegenwart. München: C. H. Beck. Price, Carolyn (2015): Emotion. Cambridge / Malden: Polity Press.

Svašek, Maruška (2010): “On the Move: Emotions and Human Mobility”. En: Journal of Ethnic and Migration Studies 36.6, pp. 865-880.

Zovko, Maja (2017): “En la otra orilla: reflexiones en torno a experiencias migratorias en España en la narrativa de los últimos años”. En: Bou, Enric / Zarco, Julieta (coords.): Fronteras y migraciones en ámbito mediterráneo. Venezia: Ca’ Foscari, pp. 57-68. 
